\title{
Estudo da viabilidade técnica de reutilização dos rejeitos da construção civil e reforma
}

\author{
Study of the technical feasibility of reuse of waste from civil construction and reform \\ Estudio de viabilidad técnica de reutilización de residuos de construcción civil y reforma
}

Recebido: 03/07/2021 | Revisado: 09/07/2021 | Aceito: 14/07/2021 | Publicado: 24/07/2021

Luana Lima Souza

ORCID: https://orcid.org/0000-0003-4209-4503 Universidade do Estado do Pará, Brasil E-mail: lulsouzaeng2015@gmail.com.

Ronilson Rosário Lobo

ORCID: https://orcid.org/0000-0001-5290-2282 Universidade do Estado do Pará, Brasil E-mail: ronilsonlobo@gmail.com.

Darci Augusto Moreira

ORCID: https://orcid.org/0000-0002-6915-9576 Universidade do Estado do Pará, Brasil E-mail: darcimireira@yahoo.com.br

Rodolfo Pereira Brito

ORCID: https://orcid.org/0000-0002-0393-5181 Universidade do Estado do Pará, Brasil E-mail: professor@ rodolfobrito.com

Antônio Pereira Júnior

ORCID: https://orcid.org/0000-0001-6241-985X Universidade do Estado doo Pará, Brasil

E-mail: antonio.junior@uepa.br

\begin{abstract}
Resumo
O segmento da construção civil é um grande vetor de desenvolvimento, entretanto ao longo da sua cadeia produtiva inevitavelmente a indústria da construção civil, gera impacto ao meio ambiente com a geração de resíduos sólidos. A mitigação seria a gestão dos RCD, a reutilização ou reciclagem do RCD são apontados como solução. Neste cenário, destaca-se como objetivo do estudo a avaliação da viabilidade técnica de aproveitamento dos RCD's, provenientes da indústria da construção civil da cidade de Paragominas/PA. O método adotando foi a pesquisa de campo como procedimento técnico. $\mathrm{O}$ estudo foi realizado em 14 bairros do município nos quais foram coletadas amostras de RCD's, destes foram produzidos corpos de prova e submetidos ao ensaio de compressão. Nos resultados, o percentual encontrado para os resíduos de classe A correspondem à oitenta e sete por cento, sendo vinte e dois por cento para argamassa e vinte e sete por cento para concreto e os outros resíduos com trinta e sete e cinquenta e quatro por cento. Do ensaio de compressão as resistências encontradas no trabalho se mostraram satisfatória para concreto com fim não estrutural, além do que ficou claro que reutilizar o agregado é um grande atrativo econômico, social e ambiental. Palavras-chave: Resíduos sólidos; RCD's; Reutilização.
\end{abstract}

\begin{abstract}
The civil construction segment is a great vector for development, however along it production chain, the civil constriction industry inevitably generates an impact on the environment with the Generation if solid waste. Mitigation would be the management of RCD, reuse or recycling of RCD are pointed out as a solution. In this scenario, the study objective is to evaluate the technical feasibility of using RCD's from the civil constriction industry in the city of Paragominas/PA. The method adopted was field research as a technical procedure. The study was carried out in 14 districts of the city in which samples of RCD's were collated, from which specimens were produced and submitted to the compression test. In the results, the percentage found for class A waste corresponds to eighty-seven percent, with twenty-two percent for mortar and twenty-seven percent for concrete and the Other ware with thirty-seven and fiftyfour percent. From the compression test, the strengths found in the work were satisfactory for concrete with a nonstructural purpose, in addition to which it was clear that reusing the aggregate is a great economic, social and environmental attraction.
\end{abstract}

Keywords: Solid waste; RCD's; Reuse.

\section{Resumen}

El segmento de la construcción civil es un gran vector de desarrollo, sin embargo a lo largo de su cadena productiva, la industria de la construcción civil genera inevitablemente un impacto em el medio ambiente con la generación de 
residuos sólidos. La mitigación sería la gestión de $\mathrm{RCD}$, la reutilización o el reciclaje de $\mathrm{RCD}$ se señalan como una solución. Em este escenario, el objetivo del estudio es evaluar la factibilidad técnica de utilizar RCD de la industria de construcción civil em la ciudad de Paragominas/PA. El método adoptado fu ella investigación de campo como procedimiento técnico, el estudio se llevó a cabo em 14 distritos de la ciudad em los que se recolectaron muestras de RCD's, de las cuales se produjeron especímenes y se sometieron a la prueba de compresión. Em los resultados, el porcentaje encontrado para residuos clase A corresponde al ochenta y siete por ciento, con veintidós por ciento para mortero y veintisiete por ciento para hormigón y el resto de residuos con treinta y siete y cincuenta y cuatro por ciento. A partir de la prueba de compresión, las resistencias encontradas em la obra fueron satisfactorias para los hormigones con finalidad no estructural, además de que quedó claro que la reutilización del árido es un gran atractivo económico, social y medioambiental.

Palabras clave: Residuos sólidos; RCD; Reutilizar.

\section{Introdução}

O segmento da construção civil se encontra entre os índices utilizado como avaliação de crescimento econômico de um país. Este setor é um grande vetor de desenvolvimento, contribuindo para da melhoria da infraestrutura e diminuindo o déficit de moradias e grande gerador de empregos. Entretanto ao longo da sua cadeia produtiva inevitavelmente a indústria da construção civil gera diversos impactos tais como impacto social, econômico e ambiental, no que se refere ao impacto ao meio ambiente podem ser citados a modificação do meio, consumo de energia, água, matéria prima e principalmente a geração de resíduos sólidos (Matuti, 2019). Estes na maioria das vezes é relacionado como rejeito, materiais que não possuem mais utilidade, por esse motivo são descartados (Rebelo, 2018) e em muitas cidades recebe destino improvisado tais como abandono em terrenos desocupados ou canteiro de ruas pouco movimentadas, estes rejeitos são levados por carregadores contratados para se livrar do entulho.

O descarte inadequado dos resíduos sólidos oriundos dos diversos processos da construção civil são os que mais demandam atenção, em virtude do crescimento acelerado e desordenado das cidades, produzem quantidades expressivas de rejeitos que são descartados, contudo este não é o único ponto negativo, a indústria da construção civil consome entre 20 a 50\% dos recursos naturais (Salomão, 2019), os usos destes recursos promovem a modificações do meio hidrológicas e hidrogeologias, dentre os quais muitas vezes são recursos não renováveis.

A mitigação seria a gestão dos RCD, que deve ser realizada no intuito de evitar abandono ou acúmulo (Leite, 2018; Silva, 2020) em locais inapropriados, no processo de gestão a reutilização ou reciclagem do RCD é apontada como uma das alternativas para minoração do problema.

Contudo a região norte do estado se encontra muito distante de alcançar o patamar da sustentabilidade, visto que na maioria das regiões não há difusão de técnicas e tecnologias voltadas para a sustentabilidade, algo que a Europa (após a segunda guerra mundial) já empregava referidas técnicas, atualmente a Holanda consegue reciclar cerca de noventa por cento dos RCD (Leite, 2018) realçando a importância em se desenvolver e propagar técnicas e tecnologias voltadas para a sustentabilidade na construção civil.

Deste modo, o referido estudo, realizou uma avaliação técnica do aproveitamento dos RCD's como agregados graúdos em concretos provenientes da construção civil da cidade de Paragominas localizada no sudeste do Estado do Pará.

\section{Materiais e Métodos}

\subsection{Fisiografia do município}

O estudo foi desenvolvido no município de Paragominas-PA, localizado a $314 \mathrm{~km}$ de Belém a capital do estado, no norte do Brasil, ocupando uma área territorial de 19.342,254 km² e a população é estimada em 113.145 habitantes segundo o Instituto Brasileiro de Geografia e Estatística[IBGE] (2019). 
Área de estudo foram os 14 bairros do município (Promissão, Angelim, Célio Miranda, Jardim Attântico, Tião Mineiro, Uraim e Juparanã). Para realizar a caracterização, a coleta foi realizada no período de um ano, durante os meses de outubro de 2018 a outubro de 2019. O método utilizado para a caracterização foi o de "casa em casa", na qual as obras foram visitadas e os resíduos separados e pesados utilizando uma balança com sensibilidade de $0,01 \mathrm{~kg}$.

\subsection{Tipo de pesquisa}

A pesquisa realizada neste estudo apresenta caráter descritivo, do qual, busca registrar, analisar, ordenar e descrever os fatos ou acontecimentos, sem alterá-los, além de buscar descobrir com que frequências os fatores ocorrem, sua natureza, suas características, causas e relação (Sakamoto \& Silveira, 2014).

Deste modo, a opção metodológica deste trabalho baseia-se em uma abordagem de natureza quantiqualitativa, pois pretende compreender o fenômeno dentro do seu contexto, procurando explicar sua origem, relações, mudanças e possíveis consequências (Matias \& Pereira, 2016; Pereira, 2018).

Quanto ao procedimento técnico utilizou-se a pesquisa de campo, tendo em vista que a obtenção dos dados foi efetuada diretamente na área de estudo, sendo o foco principal da pesquisa a sistematização do aproveitamento de resíduos da construção civil e reforma em substituição total dos agregados graúdos em concretos (Prodanov \& Freitas, 2013).

\subsection{Caracterização física dos RCD's reutilizáveis}

No total foram coletados cinquenta e uma (51) amostras de aproximadamente seiscentos e noventa e três quilos e noventa e seis gramas $(693,96 \mathrm{Kg}$ ), as amostras foram classificados in loco conforme as Resoluções do Conselho Nacional do Meio Ambiente [CONAMA](2002), e a norma Associação Brasileira de Normas Técnicas [ABNT](2004), após a classificação as amostras foram caracterizadas fisicamente segundo a ABNT (2009) que estabelece requisitos para recepção e produção dos agregados miúdos e graúdos destinados à produção de concretos de cimento de portland.

Os RCD foram classificados por categoria suas respectivas massas foram calculadas permitindo obter as frações segundo a Equação 1 do Fundação Estadual do Meio Ambiente [FEAM](2019). Após esta etapa foi determinada a massa unitária do agregado segundo ABNT (2006), segundo a Equação 2.

Para a determinação da massa específica e absorção de água foi determinada segundo a ABNT (2009) para qual foi utilizada a Equação 3 e Equação 4 respectivamente.

Para a determinação do teor de umidade as amostras foram colocadas na estufa por um período de 5 horas e depois pesadas. Em seguida estabeleceu o índice de forma do agregado graúdo pelo o método do paquímetro, conforme a ABNT(2006) utilizando a equação 5 .

Percentual de cada categoria $(\%)=\frac{P f(k g)}{P t} \times 100$

Onde: $P f=$ Peso de cada fração; $P t=$ Peso total da amostra

$$
\text { Pap }=\frac{m a r-m r}{V}
$$

Onde: $m a r=$ massa do recipiente mais amostra; $m r=$ massa do recipiente; $v=$ volume do recipiente.

$$
M s S=\frac{M}{M s-M a}
$$

Onde: $M=$ massa da amostra seca; $M s=$ massa da amostra saturada superfície seca; $M a=$ massa da saturada da superfície secasubmersa. 


$$
A b s=\frac{(M h-M o)}{M o} x 100
$$

Onde: $M h=$ massa inicial da amostra, $M o=$ massa final da amostra seca.

$$
N i=\frac{200}{\sum_{i=1}^{n} F i}
$$

$=$ número de grãos necessários para o ensaio

$N i$ = número de grãos a serem medidos na fração i;

$F=$ é a porcentagem de massa retida individual da fração i;

\subsection{Dosagem do concreto}

Mediante a caracterização física dos agregados graúdos, foi possível determinar o traço do concreto pelo método American Concrete Institute [ACI] (Ribeiro, et al.,2013). No traço do concreto o agregado graúdo foi substituído totalmente pelo RCD's, já classificados e separados por forma e dimensão do grão, no qual seguiu a classificação de brita (2, 3 e 4$)$. O traço do concreto obedeceu às exigências da ABNT (2004) que dispõe sobre requisitos básicos para o projeto de estruturas de concreto simples, armado e protendido.

\subsection{Obtenção das amostras}

Após a definição da dosagem do concreto foram confeccionados os moldes (todos em triplicata) segundo a ABNT (2015). Após a confecção, os corpos de prova foram submetidos aos ensaios segundo ABNT (2015) a partir do ensaio permitiu avaliar o carregamento máximo que o material resiste.

\section{Resultados e Discussões}

\subsection{Caracterização física do RCD's}

As quantificações dos resíduos foram realizadas segundo a Resolução CONAMA 2002 e suas alterações CONAMA (2011), estes foram separados por classes, e por bairro.

Os resultados da quantificação estão apresentados na Tabela 1 na qual estão relacionados os resíduos encontrados bem como os bairros (pontos de coleta) realizados, os resultados mostram que não há uma homogeneidade na geração dos RCD's no município, havendo elevada disparidade entre os materiais cerâmicos (tijolo com massa, tijolo sem massa, concreto e lajota) e materiais orgânicos (madeira).

O bairro que apresentou uma quantidade de resíduo significativa foi a promissão, fato que pode ser justificado por sua extensão bem como as constantes reformas nas residências, que foram perceptíveis durante as coletas. 
Tabela 1. Quantitativo dos RCD's em peso $(\mathrm{Kg})$ coletados por bairro.

\begin{tabular}{|c|c|c|c|c|c|c|c|c|c|c|c|c|}
\hline $\begin{array}{c}\text { Pontos de } \\
\text { coleta }\end{array}$ & $\mathbf{A}$ & B & $\mathrm{C}$ & D & $\mathbf{E}$ & $\mathbf{F}$ & $\mathbf{G}$ & $\mathbf{H}$ & I & $\mathbf{J}$ & $\mathbf{L}$ & $\mathbf{M}$ \\
\hline $\begin{array}{l}\text { Promissão } \\
(\mathrm{kg})\end{array}$ & 53,54 & 48,70 & 77,80 & 53,52 & 6,56 & 69,31 & 30,08 & 4,87 & 4,20 & 4,30 & 0,29 & 1,36 \\
\hline $\begin{array}{c}\text { Célio Miranda } \\
(\mathrm{Kg})\end{array}$ & 2,77 & 3,40 & 11,37 & 14,68 & - & 1,44 & - & - & - & 0,28 & - & - \\
\hline $\begin{array}{c}\text { Jardim } \\
\text { Atlântico }(\mathrm{Kg})\end{array}$ & - & - & 4,10 & 3,10 & - & - & - & - & - & - & - & - \\
\hline $\begin{array}{l}\text { Tião Mineiro } \\
\text { (Kg) }\end{array}$ & 2,37 & 2,88 & 3,70 & 3,57 & - & - & - & - & - & - & - & - \\
\hline Angelim (Kg) & 11,66 & 7,13 & 17,46 & 14,51 & - & - & 15,56 & - & 1,56 & - & - & 2,10 \\
\hline Uraim (Kg) & 15,50 & 12,76 & 41,54 & 34,20 & - & - & 12,40 & - & - & - & - & - \\
\hline Juparanã (Kg) & 14,35 & 3,78 & 34,50 & 32,75 & - & - & 18,76 & - & - & - & - & 1,81 \\
\hline Med. & 14,31 & 11,23 & 27,21 & 22,33 & 0,93 & 10,10 & 10,97 & 0,69 & 0,82 & 0,65 & 0,04 & 0,75 \\
\hline $\mathrm{Dp}(\mathrm{Kg})$ & 17,02 & 15,47 & 24,64 & 17,17 & 2,29 & 24,17 & 10,75 & 1,70 & 1,48 & 1,49 & 0,10 & 0,89 \\
\hline
\end{tabular}

Legenda: $\mathrm{A}=$ Tijolo sem massa (reboco); $\mathrm{B}=$ Tijolo com massa (reboco): $\mathrm{C}=$ Concreto; $\mathrm{D}=$ Argamassa (reboco; $\mathrm{E}=\mathrm{Massa}$ com tinta; $\mathrm{F}=$ Madeira; $\mathrm{G}=$ Lajotas; $\mathrm{H}=$ Telha; $\mathrm{I}=$ Gesso; $\mathrm{J}=$ Tubo (PVC); L = Isopor; $\mathrm{M}=$ Amianto; Med. = Média, $\mathrm{Dp}=$ desvio padrão.

Fonte: Autores (2020).

A Tabela 2 apresenta a composição dos RCD’s, com seus potenciais de reutilização e sua representação fracionária estabelecida mediante a identificação dos materiais bem como em consonância com a Resolução CONAMA (2002) e suas alterações CONAMA (2011). É possível observar que a maioria dos resíduos gerados é formada por parcelas reutilizáveis ou recicláveis (classes A e B).

De acordo com a Tabela 2 os dados que apresentam maior percentual dos materiais reutilizáveis correspondem aproximadamente ao percentual de setenta e cinco por cento $(75,72 \%)$, os materiais recicláveis correspondem à vinte e três por cento $(23,45 \%)$, os materiais que destinados ao aterro correspondem aproximadamente, ao percentual de um por cento $(0,79 \%)$, como os dados obtidos é importante realçar a relevância da triagem voltada para a reutilização e reciclagem na busca de um gerenciamento dos resíduos sólidos eficiente.

Tabela 2. Composição gravimétrica e a classificação do RCD segundo o Conama $\mathrm{n}^{\circ} 307$ e $\mathrm{n}^{\circ} 431$, separados por classe e percentagem em peso.

\begin{tabular}{cllcl}
\hline Classe & Material & \% & \% por classe & Destinação \\
\hline & Argamassa & 22,52 & & Reutilizáveis \\
A & Concreto & 27,44 & & Reutilizáveis \\
& Telha & 0,70 & & Reciclagem \\
& Lajota & 11,08 & & Reciclagem \\
& Tijolo sem massa & 14,43 & $\Sigma=87,50$ & Reutilizáveis \\
& Tijolo com massa & 11,33 & & Reutilizáveis \\
& Madeira & 10,19 & & Reciclagem \\
& Gesso & 0,83 & $\Sigma=11,61$ & Reciclagem \\
& Tubo/PVC & 0,65 & \multirow{2}{*}{$\Sigma$} & Reciclagem \\
& Isopor & 0,04 & & Aterro \\
& Amianto & 0,75 & $\Sigma=0,04$ & Aterro \\
\hline
\end{tabular}

Fonte: Autores (2020). 
Os dados apresentados estão condizentes com estudos da área que consideram que sessenta e três por cento (63\%) de material descartado na obra é material reciclável e reutilizável, deste volume vinte e nove por cento (29\%) é composto de concreto e bloco, e sete por cento (7\%) oriundos de itens variados (Alves, 2015; Bessa, 2019).

Neste trabalho o percentual encontrado para os resíduos de classe A correspondem à oitenta e sete por cento (87,50\%), sendo vinte e dois por cento $(22,52 \%)$ para argamassa e vinte e sete por cento $(27,44 \%)$ para concreto e outros resíduos com trinta e sete e cinquenta e quatro por cento $(37,54 \%)$, os RCD's não foram coletados exclusivamente de obras novas mais também de obras de ampliação e manutenção.

\subsection{Dosagem de concreto}

A Tabela 3 representa a análise granulométrica com os percentuais obtidos dos materiais retido nas peneiras classificadas como brita 2, 3 e 4 conforme estabelece a ABNT(2003), referente a determinação da composição granulométrica dos agregados. Para obter as porcentagens utilizou-se a Equação 2:

Equação 02: Determinação granulométrica $(\%)=\frac{\text { material retido }(\mathrm{mr})}{\text { material peneirado }(\mathrm{mp})} \times 100$

Tabela 3. Porcentagem retida nas peneiras.

\begin{tabular}{ccc}
\hline Peneiras & \% retido de Massa & \% retido de Concreto \\
\hline Brita 2 & 19,67 & 27,06 \\
19,0-25,0mm & & \\
Brita 3 & 24,18 & 18,05 \\
$25,0-38,0 \mathrm{~mm}$ & & 21,96 \\
Brita 4 & 27,48 & \\
$38,0-64,0 \mathrm{~mm}$ & & \\
\hline
\end{tabular}

Fonte: Autores (2020).

Com os agregados analisados granulometricamente, foi possível determinar os valores da massa específica, massa unitária e teor de umidade. Os dados obtidos estão expostos na Tabela 4 Ditz e Amaro (2019) encontraram resultados similares de massa específica e unitária, onde os autores utilizaram os RCD's graúdos para confecção dos corpos de provas e os valores ficaram em torno de 1 e 2 respectivamente, como o do presente estudo.

Tabela 4. Valores de massa específica, massa unitária e teor de umidade.

\begin{tabular}{lclc}
\hline Red - brita & \multicolumn{1}{c}{$\begin{array}{c}\text { Massa específica } \\
\left(\mathbf{k g} / \mathbf{d m}^{3}\right)\end{array}$} & $\begin{array}{c}\text { Massa unitária } \\
\left(\mathbf{k g} / \mathbf{d m}^{3}\right)\end{array}$ & $\begin{array}{c}\text { Teor de } \\
\text { umidade }\left(\mathbf{k g} / \mathbf{d m}^{3}\right)\end{array}$ \\
\hline RCD - brita 2 - concreto & 2,024099835 & 1,060573333 & 5,30 \\
RCD - brita 2 - argamassa & 1,770172629 & 0,99656 & 4,27 \\
RCD - brita 3 - concreto & 2,118699953 & 1,003206667 & 4,74 \\
RCD - brita 3 - argamassa & 1,867693257 & 1,098373333 & 2,57 \\
RCD - brita 4 - concreto & 1,992447095 & 1,166213333 & 4,89 \\
RCD - brita 4 - argamassa & 1,860800268 & 1,264533333 & 2,00 \\
Areia & - & - & 5,18 \\
\hline
\end{tabular}

Fonte: Autores (2020).

Quanto ao índice de forma, este avalia a qualidade do agregado graúdo em relação a sua forma o que influencia as características de trabalhabilidade, foi calculado para cada RCD's classificado, a qual verificou que os resíduos se enquadram 
como forma cúbica, e os valores encontrados estão dentro do limite e de acordo com a norma ABNT (2006)que estabelece como valor máximo o índice de forma 3, além do mais a forma cúbica de acordo Bauer (2013) é considerada como forma ótima para a produção do concreto e o seu valor máximo é igual a 1,8. Os valores encontram-se na Tabela 5.

Tabela 5. Valores encontrados a partir do método do paquímetro.

\begin{tabular}{ll}
\hline & \multicolumn{1}{c}{ Índice de forma } \\
\hline Britas & Índice \\
RCD - brita 2 - concreto & 1,8139122 \\
RCD - brita 2 - argamassa & 1,680675 \\
RCD - brita 3 - concreto & 1,65054655 \\
RCD - brita 3 - argamassa & 1,645347303 \\
RCD - brita 4 - concreto & 1,8412 \\
RCD - brita 4 - argamassa & 1,6675549985 \\
\hline
\end{tabular}

Fonte: Autores (2020).

Com a obtenção dos valores da massa unitária, específica, teor de umidade, foi calculado o traço do concreto para a produção dos 18 corpos de prova, o traço para cada RCD's - brita consta na Tabela 6.

Tabela 6. Valores do traço do concreto para confecção dos corpos de prova.

\begin{tabular}{lllll}
\hline & \multicolumn{3}{c}{ Traço do concreto } & \\
\hline Britas & Cimento (kg) & Areia $(\mathrm{kg})$ & Resíduo (kg) & Água (kg) \\
RCD - brita 2 - concreto & 0,55735 & 0,6366507 & 1,082 & 0,30615 \\
RCD - brita 2 - argamassa & 0,55735 & 0,5982 & 1,0170303 & 0,30615 \\
RCD - brita 3 - concreto & 0,54165 & 0,6253781 & 1,0631412 & 0,2983 \\
RCD - brita 3 - argamassa & 0,54165 & 0,6846927 & 1,163998 & 0,2983 \\
RCD - brita 4 - concreto & 0,51339 & 0,7651395 & 1,327435 & 0,2826 \\
RCD - brita 4 - argamassa & 0,51339 & 0,8466225 & 1,4393446 & 0,2826 \\
\hline
\end{tabular}

Fonte: Autores (2020).

Com o cálculo do traço do concreto se produziu os corpos de provas, ressaltando que houve algumas alterações no traço calculado, pois devido ao agregado reutilizado apresentar mais porosidade, propende absorver uma quantidade de água maior.

Proporcionando assim, uma massa pouco plástica, gerando um corpo de prova com muitas falhas no preenchimento do molde. Tendo visto esta falha, verificou a necessidade de correção do traço, no qual foi acrescentado cimento, areia, água e resíduo, a Tabela 7 apresenta o traço com correção.

Tabela 7. Valores acrescidos do traço para confecção das amostras.

\begin{tabular}{lcccc}
\hline \multicolumn{3}{c}{ Valores acrescidos } \\
\hline Britas & Areia $(\mathrm{kg})$ & Cimento $(\mathrm{kg})$ & Água(kg) & Resíduo(kg) \\
RCD - brita 2 - concreto & 0,60 & 0,55 & 0,403 & 1 \\
RCD - Brita 2 - argamassa & 0,2655 & 0,2317 & 0,2 & 0,28 \\
RCD - Brita 3 - concreto & 0,512 & 0,47 & 0,5 & 0,99157 \\
RCD - Brita 3 - argamassa & 0,68469 & 0,54199 & 0,4583 & 0,58199 \\
RCD - Brita 4 - concreto & 0,38256 & 0,25695 & 0,1413 & Não houve acréscimo \\
RCD - Brita 4 - argamassa & 0,84662 & 0,51339 & 0,6226 & Não houve acréscimo \\
\hline
\end{tabular}

Fonte: Autores (2020). 


\subsection{Ensaio do agregado}

Para verificar a resistência que o material suporta, os corpos de prova foram submetidos ao ensaio de compressão axial. Os resultados obtidos no teste estão expressos na tabela 08 , já com as médias dos 3 corpos de provas confeccionados de cada RCD's classificado.

Quanto ao comportamento das amostras em relação a resistência, observou que houve apenas uma variação das amostras correspondente a brita 4, no entanto os outros valores se aproximaram não tendo variações significativas.

A classificação referente a brita 3 se apresentou como possivelmente o tamanho de agregado graúdo que mais contribui para a resistência mecânica (tanto para o RCD de concreto e massa), contudo o RCD de argamassa de tamanho referente a brita 3 apresentou melhor desempenho em relação as outras composições utilizadas.

O RCD's referente a brita 4 de argamassa, não atendeu aos requisitos da norma, pois o valor da resistência ficou em torno de 6,60 Mpa, abaixo do que prevê a norma para fins não estruturais.

Tabela 8. Resultado da ruptura a compressão dos corpos de prova de concreto e argamassa reutilizado.

\begin{tabular}{lll}
\hline & \multicolumn{2}{c}{ Propriedades da Brita } \\
\hline Britas & Substituição & Fcm,j (MPa) \\
RCD - brita 2 - concreto & $100 \%$ & 13,18 \\
RCD- brita 2 - argamassa & $100 \%$ & 12,87 \\
RCD - brita 3 - concreto & $100 \%$ & 12,69 \\
RCD - brita 3 - argamassa & $100 \%$ & 15,77 \\
RCD - brita 4 - concreto & $100 \%$ & 13,04 \\
RCD - brita 4 - argamassa & $100 \%$ & 6,60 \\
\hline
\end{tabular}

Legenda :Fcm,j = 28: resistência à compressão média aos 28 dias. Fonte: Autores (2020).

No estudo realizado por Zangeski et al. (2017) os valores encontrados são semelhantes ao do presente trabalho, onde a resistência final foi de 14,24 MPa para um período de 28 dias, ressaltando que os corpos de prova foram confeccionados com resíduos recicláveis, diferentemente do trabalho em questão que optou pela reutilização dos resíduos.

De acordo com Domenico et al. (2018) os agregados reciclados e reutilizados possuem elevada porosidade, devido possuir ao alto teor de material cerâmico nos resíduos, esta alta porosidade do material atribui ao concreto perda na resistência à compressão, bem como, o aumento da permeabilidade que pode interferir no uso de concreto estrutural, havendo então, possibilidade de utilização em estruturas pouco expostas e com menor agressividade ambiental.

Neste contexto, Tavares e Kazmierczak (2016), evidenciam também que os RCD’s com maior absorção de água e porosidade apresentam baixa resistência, contudo, podem ser utilizados em pavimentos permeáveis, visto que, são estruturas que demandam o elevado índice de drenagem.

Os resultados encontrados neste trabalho, estão de acordo com a aplicação estabelecida pela ABNT (2015) que define uma resistência de 10 a $15 \mathrm{MPa}$ para concreto de uso não estrutural.

Os resultados obtidos também se enquadram na norma ABNT (1989), que estabelece como tensão admissível 12 à 17 MPa para alvenaria não armada, essa alvenaria apresenta baixa resistência e necessita de estruturas para ser utilizada, como vigas, pilar e cinta. A Tabela 9 mostra uma análise comparativa da média do corpo de prova que obteve maior resistência neste trabalho, com os estudos dos autores citados acima, e as resistências exigências pela ABNT (2015), ABNT (1989) para corpos de prova rompidos no período aos 28 dias. 
Tabela 9. Análise comparativa do ensaio de compressão.

\begin{tabular}{|c|c|c|c|}
\hline $\begin{array}{l}\text { Resistência } \\
\text { (MPa) }\end{array}$ & Período & $\begin{array}{ll}\text { Substituição } & \text { do } \\
\text { RCD's } & \\
\end{array}$ & Autores e normas \\
\hline 16,5 & 28 dias & $100 \%$ & Casaroto et al. (2016) \\
\hline 14,24 & 28 dias & $100 \%$ & Zangeski et al. (2017) \\
\hline 9 e 13 & 28 dias & $100 \%$ & Gomes et al. (2015) \\
\hline 10 á 15 & - & - & NBR 8953:2015 \\
\hline 12 á 17 & - & & NRB 10837:1989 \\
\hline 15,7 & 28 dias & $100 \%$ & Resultado encontrado no trabalho. \\
\hline
\end{tabular}

Fonte: Autores (2020).

Portanto, os resultados encontrados da resistência final pelos autores, se assemelham com a resistência do trabalho em questão, não havendo discrepâncias consideráveis e enquadrando do que preestabelecem as normas. No trabalho de Santos et al. (2016), foi verificado que quanto mais elevado o teor do material adicionado a mistura, menor é o índice de vazio, acarretando assim um maior empacotamento e compacidade, e quanto for maior a compacidade, maior será os níveis de resistência à compressão.

\section{Conclusão}

Portanto, a reutilização dos RCD’s se mostrou satisfatória para concreto com fim não estrutural, tendo em vista que as resistências encontradas no trabalho estão de acordo com que preestabelecem as normas, além do que ficou claro que reutilizar o agregado é um grande atrativo econômico na construção civil, pois demanda menos custos na obra.

Outro ponto relevante é a questão ambiental, uma vez que o reaproveitamento reduz a geração dos agregados no meio ambiente e consequentemente minimiza o gasto público com a coleta dos resíduos descartados em locais inapropriados e reduz a quantidade de resíduo a ser depositado em aterro, além de diminuir os vetores de doenças que são gerados com o acervo de resíduos, colaborando desta forma com o lado social.

Deste modo, é válido ressaltar que o trabalho é de suma relevância tanto para questão social, ambiental e econômica, e que aplicação de RCD’s como agregado gráudo pode ser utilizado no município de Paragominas para confecção de calçadas, pavimentos, contrapisos, blocos, pois são estruturas que não demandam o valor de resistência alto.

\section{Referências}

Alves, F. R. F. (2015) Estimativa da geração de resíduos da construção civil no município de Campo Mourão - PR. Trabalho de Conclusão de Curso. Universidade Tecnológica Federal do Paraná.

Associação Brasileira de Normas Técnicas. (2004). NBR 10004: Resíduos sólidos - classificação.

Associação Brasileira de Normas Técnicas. (1987), NBR 10837: Cálculo de alvenaria de blocos vazados de concreto.

Associação Brasileira de Normas Técnicas. (2015), NBR 5738: Concreto - Procedimento para moldagem e cura de corpos de prova Especificação.

Associação Brasileira de Normas Técnicas (2015), NBR 5739: Concreto - Ensaio de compressão de corpos de prova cilíndricos.

Associação Brasileira de Normas Técnicas. (2004), NBR 6118: Projeto de estrutura de concreto - procedimentos.

Associação Brasileira de Normas Técnicas. (2003) NBR 248: Agregados - Determinação da composição granulométrica.

Associação Brasileira de Normas Técnicas. (2006), NBR NR 45: Agregados - Determinação da massa unitária e do volume de vazios.

Associação Brasileira de Normas Técnicas. (2009), NBR 7211: Agregados para concreto - Especificação.

Associação Brasileira de Normas Técnicas. (2008), NBR 7809: Agregado graúdo determinação do índice de forma pelo método do paquímetro: método de ensaio.

Associação Brasileira de Normas Técnica (2015), NBR 8953: Concreto Para Fins Estruturais - Classificação Pela Massa Específica, Por Grupos De Resistência E Consistência. 
Associação Brasileira de Normas Técnicas. (2006), NBR NR 45: Agregados - Determinação da massa unitária e do volume de vazios.

Bauer, L. A. F. (2013) Materiais de Construção - Novos Materiais para Construção Civil. (5a ed.), LTC.

Bessa, S. A. L., Mello, T. A. G., \& Lourenço, K. K. (2019). Análise quantitativa e qualitativa dos resíduos de construção e demolição gerados em Belo Horizonte. urbe. Revista Brasileira de Gestão Urbana, 11, 10.1590/2175-3369.011.e20180099, 1-16.

Brasil. Conselho Nacional do Meio Ambiente-CONAMA. (2002), Resolução n. 307. Estabelece sobre as diretrizes, critérios e procedimentos para a gestão dos resíduos da construção civil. Diário Oficial da União, www.mma.gov.br/port/conama/legiabre.cfm.

Brasil. Ministério do Meio Ambiente (2010), Lei 12.305/2010. Institui a Política Nacional de Resíduos Sólidos, altera a Lei no 9.605, de 12 de fevereiro de 1998, e dá outras providências. Diário Oficial da União, http://www.planalto.gov.br/ccivil_03/_ato2007-2010/2010/lei/112305.htm.

Ditz, J. D., \& maro, L. C. (2019). Análise das propriedades mecânicas do concreto de alta resistência com agregados de construção e demolição. Revista de Engenharia e Tecnologia, v. 11, https://revistas2.uepg.br/index.php/ret/article/view/13742.

Domenico, P. Di., Lima, T. T., Castro, M. R., \& Castro, N. M (2018). Influência do agregado miúdo reciclado na resistência à compressão e porosidade do concreto. Revista Internacional de Ciências, 8, 129-147. 10.12957/ric.2018.33254.

Fundação Estadual do Meio Ambiente (2019). Cartilha de Orientações: Estudo Gravimétrico de Resíduos Sólidos Urbanos. Belo Horizonte, CDU 6284:32, 119.

Instituto Brasileiro de Geografia e Estatística, (2019). https://cidades.ibge.gov.br/brasil/pa/paragominas/panorama.

Jorge Luis Oliveira Silva. (2020). Prática sustentável nos canteiros de obra brasileiros: uma discussão sobre a reutilização de resíduos oriundos da construção civil. Brazilian Journals of Business. 2. 2841-2846. 10.34140/bjbv2n3-066.

Leite, I. C. A., Damasceno, J. L. C., Reis, A. M, \& lvim, M. (2018). Gestão de resíduos na construção civil: um estudo em Belo Horizonte e região metropolitana. Revista eletrônica de Engenharia Civil. REEC. 14, 14(1). https://doi.org/10.5216/reec.v14i1.44439, 159-175.

Matuti, B. B., \& Santana, G. P. (2019). Reutilização de resíduos de construção civil e demolição na fabricação de tijolo cerâmico-uma revisão. Scientia Amazônia, Amazonas, 8,1-13. http//www.scientia-amazonia.org.

Matias,Pereira, J. (2016) Manual de metodologia da pesquisa científica. (4a ed.), Atlas.

Pereira, A. S. et al. (2018) Metodologia da pesquisa científica. UFSM.

Prodanov, C. C., \& Freitas, E. C. (2013) Metodologia do trabalho científico: métodos e técnicas da pesquisa e do trabalho acadêmico. (2a ed.), Feevale.

Rebêlo, M. V. S., Peres, R., Duarte, C. K. A. R., Moreira, F. N. C., \& Ferreira, J. F. H. (2018). Diagnóstico da situação dos resíduos de construção civil no campus da Universidade Federal do Pará, Belém/Pará. Brazilian Applied Science Review., 1849-1856. https//www.brazilianjournals.com.index.php.

Ribeiro, C. C., Pinto, J. D. S., \& Starling, T. 2013. Materiais de construção civil. UFMG.

Santos, S. B. J. S., Torres, D. A., Lima, P. E. E., Carvalho. M. C., \& Júnior, S. S. A (2016). Utilização De Resíduos De Corpos De Prova Em Substituição do Agregado Graúdo de Concretos. Revista Interscientia, 4, https://periodicos.unipe.br/index.php/interscientia/article/view/524.

Salomão, P. E. A., Malagute, L. S., Lorentz, L. P. A., \& Paula, L. T. G (2019). Reutilização dos resíduos gerados pela construção civil: uma breve revisão. Res., Soc. V8, 10.33448/rsd-v8i10.1366, 1-13.

Sakamoto, C. K., \& Silveira, I. O. (2014) Como fazer projetos e Iniciação Científica. Paulus.

Tavares, L. M., \& Karzmierczak, C. S (2016). Estudo da influência dos agregados de concreto reciclado em concretos permeáveis. Ibracon Structures and Materials Journal, 10.1590/S1983-41952016000100006, 75-90.

Zangeski, D. S. O., Novais, J. W. Z., Silva, J. P. S., Ferreira, R. S., \& Melo, F. C. L (2017). Estudo comparativo entre a resistência a compressão do concreto com agregado convencional calcário e com agregados recicláveis. Ensaios e Ciência: Ciências Biológicas, Agrárias e da Saúde, 21, 64 - 69, http//.redalyc.org/articulo.oa?id=26053412002 